\title{
A central shunt to rehabilitate diminutive pulmonary arteries in patients with pulmonary atresia with ventricular septal defect
}

\author{
Hyungtae Kim, MD, ${ }^{a}$ Si Chan Sung, MD, ${ }^{a}$ Kwang Ho Choi, MD, ${ }^{a}$ Hyoung Doo Lee, MD, ${ }^{b}$ \\ Gil Ho Ban, MD, ${ }^{\mathrm{b}}$ and Yun Hee Chang, $\mathrm{MD}^{\mathrm{c}}$
}

Objectives: We evaluated our clinical experiences on rehabilitation of native pulmonary arteries (PAs) with a central shunt using an expanded polytetrafluoroethylene (ePTFE) tube graft in management of pulmonary atresia with ventricular septal defect (VSD) and major aortopulmonary collateral arteries (MAPCAs) with diminutive PAs.

\begin{abstract}
Methods: From March 1993 to June 2013, a total of 28 consecutive patients underwent surgery for pulmonary atresia with VSD and MAPCAs. We identified 15 patients who underwent a central shunt procedure using an ePTFE tube graft. Median age and weight at the initial operation were 1.91 months and $5.22 \mathrm{~kg}$, respectively. Ligation of MAPCAs was performed in 3 patients concomitantly. The techniques used were a U-shaped central shunt in 13 patients, and a side-to-side aorto-ePTFE tube graft anastomosis in 2 patients.
\end{abstract}

Results: There was no surgical mortality, and no shunt occlusion. The mean follow-up duration was $70.7 \pm 67.1$ months. Complete repair was achieved in 13 patients (13 of 14 of the follow-up patients; $92.9 \%$ ), and the remaining patient is waiting for complete repair. The median age at complete repair was 19.4 months. The mean PA index before the initial central shunt procedure was $22.7 \pm 13.2 \mathrm{~mm}^{2} / \mathrm{m}^{2}$, which increased to $149.4 \pm 86.6 \mathrm{~mm}^{2} / \mathrm{m}^{2}$ at the final recordings before shunt division, and $185.9 \pm 84.0 \mathrm{~mm}^{2} / \mathrm{m}^{2}$ before complete repair. There were 2 late mortality cases. The overall survival rates were $92.9 \%, 82.5 \%$, and $82.5 \%$, at 1,5 , and 10 years, respectively.

Conclusions: A central shunt, using an ePTFE tube graft, is an effective initial palliative procedure for rehabilitation of the diminutive PAs in patients with pulmonary atresia with VSD and MAPCAs. (J Thorac Cardiovasc Surg 2015;149:515-20)

See related commentary on pages 520-1.

Supplemental material is available online.

Patients with pulmonary atresia with ventricular septal defect (VSD) and major aortopulmonary collateral arteries (MAPCAs) have atresia of the pulmonary valve with hypoplastic or absent intrapericardial pulmonary arteries

\footnotetext{
From the Department of Thoracic and Cardiovascular Surgery, ${ }^{a}$ Research Institute for Convergence of Biomedical Science and Technology, and Department of Pediatrics, ${ }^{\text {b }}$ Pusan National University Yangsan Hospital, Mulgeum-eup, Yangsan-si, Gyeongsangnam-do, Republic of Korea; and Department of Thoracic and Cardiovascular Surgery, ${ }^{\mathrm{c}}$ St. Mary's Hospital, The Catholic University of Korea, Seoul, Republic of Korea.

This work was supported for 2 years by a Pusan National University Research Grant. Disclosures: Authors have nothing to disclose with regard to commercial support.

Received for publication Aug 4, 2014; revisions received Sept 25, 2014; accepted for publication Oct 4, 2014; available ahead of print Nov 7, 2014.

Address for reprints: Si Chan Sung, MD, Department of Thoracic and Cardiovascular Surgery, Pusan National University Yangsan Hospital, Mulgeum-eup, Yangsan-si, Gyeongsangnam-do 626-770, Republic of Korea (E-mail: scsung21@han mail.net).

$0022-5223 / \$ 36.00$

Copyright (c) 2015 by The American Association for Thoracic Surgery

http://dx.doi.org/10.1016/j.jtcvs.2014.10.033
}

(PAs), and pulmonary blood flow depends on collateral arteries arising from the aorta or its branches. ${ }^{1,2}$ Pulmonary atresia with VSD and MAPCAs is a highly complex form of congenital heart disease. ${ }^{3}$ The majority of these patients have abnormal arborization of the PAs, and small or even complete absence of intrapericardial PAs. ${ }^{4}$

We routinely perform preoperative cardiac catheterization with/without computed tomography (CT) angiography, in patients identified with pulmonary atresia with VSD and MAPCAs, to define the anatomy and sources of pulmonary blood flow. We have identified 3 specific groups of patients, and have focused on the patients with diminutive PAs. A central shunt procedure using an expanded polytetrafluoroethylene (ePTFE) tube graft was performed as an initial palliation to rehabilitate native PAs for this group of patients in the early infancy period, regardless of oxygen saturation level. This study evaluated the effectiveness of the central shunt using an ePTFE tube graft, focusing on rehabilitation of native PAs in the management of pulmonary atresia with VSD and MAPCAs with diminutive PAs.

\section{PATIENTS AND METHODS \\ Patients}

This study was approved by the Institutional Review Board at Pusan National University Yangsan Hospital (approval No. 05-2013-063). From 


$$
\begin{aligned}
& \text { Abbreviations and Acronyms } \\
& \begin{aligned}
\text { CT } & =\text { computed tomography } \\
\text { ePTFE } & =\text { expanded polytetrafluoroethylene } \\
\text { LPA } & =\text { left pulmonary artery } \\
\text { MAPCA } & =\text { major aortopulmonary collateral artery } \\
\text { MPA } & =\text { main pulmonary artery } \\
\text { PA } & =\text { pulmonary artery } \\
\text { RPA } & =\text { right pulmonary artery } \\
\text { RV } & =\text { right ventricle } \\
\text { VSD } & =\text { ventricular septal defect }
\end{aligned}
\end{aligned}
$$

March 1993 to June 2013, a total of 28 consecutive patients (11 males and 17 females) underwent surgery for pulmonary atresia with VSD and MAPCAs. We routinely performed preoperative cardiac catheterization with/without CT angiography before the initial operation. There were 3 groups of patients: (1) patients without central native PAs $(\mathrm{n}=4$, $14.3 \%)$; (2) patients with diminutive PAs $(\mathrm{n}=21,75 \%)$, with 17 who underwent a central shunt procedure (1 patient in another hospital), and 4 who underwent a Blalock-Taussig (BT) shunt procedure (2 of these had early experiences, 1 had previous bilateral unifocalization in another hospital, and 1 had almost no main pulmonary artery (MPA) segment with a sizable right pulmonary artery [RPA]); and (3) patients with a sizable MPA ( $\mathrm{n}=3,10.7 \%)$, shown in Figure 1. A diminutive PA is usually defined $^{5-7}$ as an MPA of size $<3-4 \mathrm{~mm}$, and a PA index $<20-30 \mathrm{~mm}^{2} / \mathrm{m}^{2}$.

We focused on the second group of patients, and identified 16 patients who underwent a central shunt procedure in our hospital as an initial palliation for rehabilitation of diminutive native PAs. Of the 16 patients, 1 was excluded who had undergone a direct anastomosis between the ascending aorta and MPA. Therefore, we ultimately enrolled 15 patients, 8 men and 7 women, who underwent a central shunt procedure using an ePTFE tube graft as an initial palliation. The median age and weight at the initial operation were 1.91 months (range: 0.2-26.36 months) and
$5.22 \mathrm{~kg}$ (range: $2.3-12.0 \mathrm{~kg}$ ), respectively. The patients' characteristics are summarized in Table 1.

\section{Surgical Techniques}

Ligation of MAPCAs was performed in 3 patients concomitantly. All 3 patients had symptoms of heart failure or overcirculation to the pulmonary vascular bed with/without cyanosis, and the other 12 patients had cyanosis. The conduits used in the central shunt were a $4-\mathrm{mm}$ (10 patients), a $3.5-\mathrm{mm}$ (4 patients), and a 5-mm (1 patient) ePTFE tube graft (W. L. Gore and Associates, Flagstaff, Ariz). The techniques used in the central shunt procedure were a U-shaped central shunt in 13 patients (Figure 2, A), and a side-to-side aorto-ePTFE tube graft anastomosis in 2 patients (Figure 2, B) ${ }^{8,9}$ In a U-shaped central shunt, the MPA is divided very near right ventricle (RV), and anastomosed with an ePTFE tube graft in end-to-end fashion using 8-0 Prolene sutures (Ethicon, Somerville, NJ). Then, the other end of the graft is connected to the anterior wall of the ascending aorta in an end-to-side fashion. In a side-to-side aorto-ePTFE tube graft central shunt, a longitudinal incision is made at the anterior surface of the divided MPA, and one end of the graft is connected to this incision. Then the graft is anastomosed to the ascending aorta in a side-to-side fashion, with clipping of the open end. A cardiopulmonary bypass was not required for any of the patients. We routinely used heparin infusion during the immediate postoperative period, and the patients were put on aspirin therapy thereafter.

The complete repair with VSD closure was considered when (1) no sizable MAPCAs remained, (2) more than approximately two thirds of the bronchopulmonary segments were connected to the central pulmonary blood supply, ${ }^{5}$ and (3) the direction of the shunt flow through the VSD, as shown on preoperative echocardiography, was left-to-right. Other studies have evaluated preoperative ${ }^{10}$ or intraoperative ${ }^{11}$ pulmonary blood flow to ensure VSD closure, but we did not.

\section{Statistical Analysis}

Data were collected and managed using Microsoft Excel 2010 and analyzed using SPSS 17.0 (SPSS Inc, Chicago, Ill). They are reported as

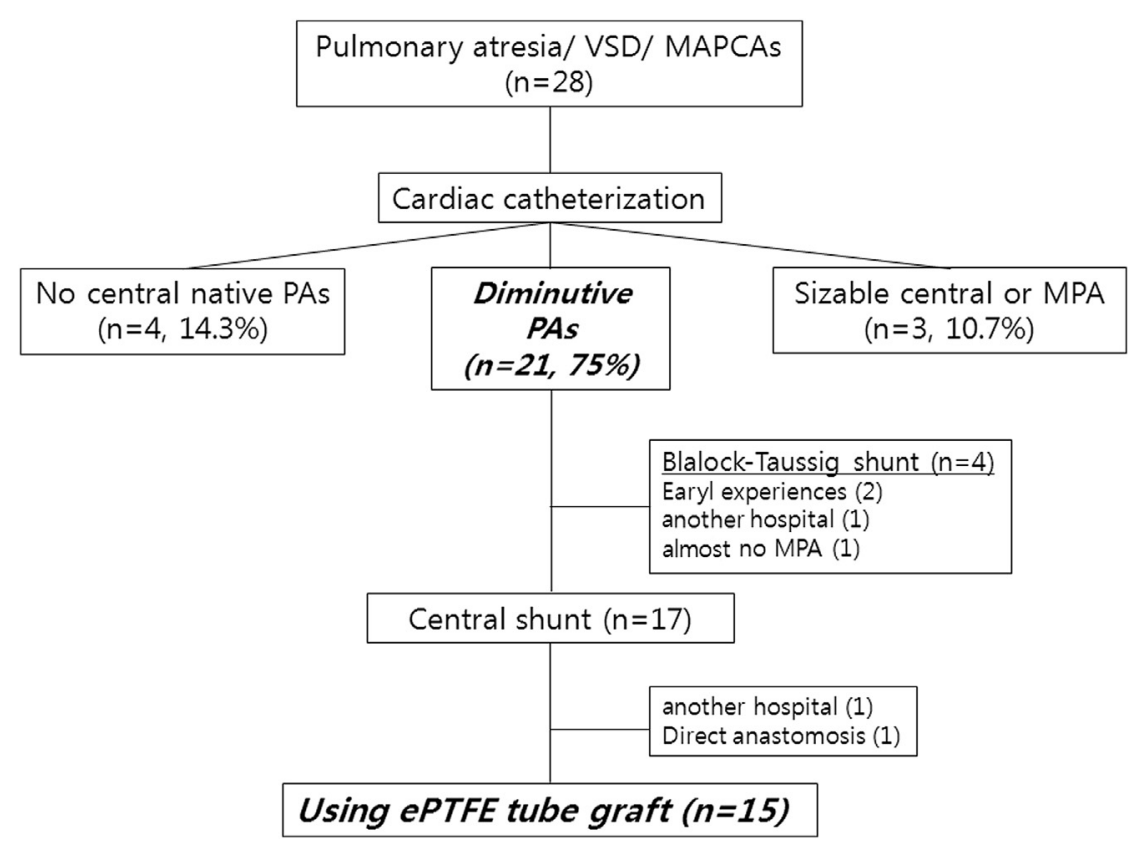

FIGURE 1. Three groups of patients with pulmonary atresia with ventricular septal defect (VSD) and major aortopulmonary collateral arteries (MAPCAs) in our study. Percentages shown are the proportion of total patients in our experience. VSD, Ventricular septal defect; MAPCA, major aortopulmonary collateral artery; $P A$, pulmonary artery; $M P A$, main pulmonary artery; $P P T F E$, expanded polytetrafluoroethylene. 
TABLE 1. Patients' demographics $(\mathbf{n}=15)$

\begin{tabular}{lc}
\hline \multicolumn{1}{c}{ Variable } & Value or no. \\
\hline Age at the initial operation $(\mathrm{mo})$ & $\begin{array}{c}\text { Median } 1.91 \\
\text { (range: } 0.2-26.36)\end{array}$ \\
Weight at the first operation $(\mathrm{kg})$ & Median 5.22 \\
& (range: $2.3-12.0)$ \\
Sex (male:female) & $8: 7$ \\
Preoperative PA index (Nakata index) & Median 19.3 (range: \\
$\quad$ PA cross-sectional areas in $\mathrm{mm}^{2} / \mathrm{BSA}$ in $\mathrm{m}^{2}$ ) & $2.92-49.63$; mean: \\
& $22.7 \pm 13.2)$ \\
MAPCAs count & Mean 3.1 1.4 \\
& $($ range: $1-6)$ \\
Associated cardiac or noncardiac anomalies & 10 \\
Right aortic arch & 6 \\
CATCH 22 & 1 \\
Bilateral superior vena cava & 1 \\
Partial anomalous pulmonary venous return & 1 \\
Duodenal atresia & \\
Preoperative procedures (1/16; $6.3 \%)$ & 1 \\
Stent insertion in proximal MAPCA & \\
\hline
\end{tabular}

PA, Pulmonary artery; $B S A$, body surface area; $M A P C A$, major aortopulmonary collateral artery; $C A T C H$, Cardiac abnormality, Abnormal facies, Thymic aplasia, Cleft palate, and Hypocalcemia/hypoparathyroidism.

median (range) or mean \pm standard deviation, as appropriate. The Kaplan-Meier method was used to analyze overall survival rate.

\section{RESULTS}

There was no surgical mortality in this cohort of 15 patients who underwent the creation of a central shunt using an ePTFE tube graft, and no shunt occlusion occurred after the operation. The average duration of patients' hospital stay from the date of the operation to the date of discharge was $37.9 \pm 37.5$ days (range: 10-121 days; median: 16 days). One patient was referred to another hospital, after undergoing an initial central shunt procedure, because of a nonmedical problem.

Figure 3 shows the staged operations of all 15 patients after the central shunt procedure. The mean follow-up duration was $70.7 \pm 67.1$ months (range: 9.7-211.5 months). Complete repair was achieved in 13 patients
(13 of 14 follow-up patients; $92.9 \%$ ), and the remaining patient is waiting for complete repair. The median age at complete repair was 19.4 months (range: 5.4-86.2 months). The time interval between the initial central shunt procedure and complete repair was $23.6 \pm 19.0$ months (range: 3.7-67.2 months; median: 17.7 months). The mean number of operations required to achieve complete repair was $3.77 \pm 1.24$ (range: 2-6).

Measurements of the right and left branch PAs were recorded from angiograms, direct measurements during the operation, and/or CT angiography. The mean PA index before the initial central shunt procedure was $22.7 \pm 13.2 \mathrm{~mm}^{2} / \mathrm{m}^{2}$ (range: $2.9-49.6 \mathrm{~mm}^{2} / \mathrm{m}^{2}$ ). This index increased to $149.4 \pm 86.6 \mathrm{~mm}^{2} / \mathrm{m}^{2}$ (range: $61.9-406.5 \mathrm{~mm}^{2} / \mathrm{m}^{2}$ ), and to $185.9 \pm 84.0 \mathrm{~mm}^{2} / \mathrm{m}^{2}$ (range: $64.1-395.7 \mathrm{~mm}^{2} / \mathrm{m}^{2}$ ) at the last recording before shunt division and complete repair (VSD closure), respectively (Figure 4). The RPA diameter increased from a mean of $1.95 \pm 0.68 \mathrm{~mm}$ to $6.04 \pm 1.91 \mathrm{~mm}$, and the LPA diameter increased from a mean of $1.82 \pm 0.65 \mathrm{~mm}$ to $5.79 \pm 2.02 \mathrm{~mm}$ between the central shunt and the shunt division for a median period of 9.7 months (range, 1.4-59.8 months) (Figure E1, $A$ and $B$ ). A stent was inserted in MAPCA, which had communications with native PAs, in 1 patient before the initial central shunt, to rehabilitate very small native PAs. However, that procedure was not effective in enlarging the native PAs. This patient underwent a central shunt procedure at age 7.4 months, and an RV-PA conduit formation with RPA and LPA unifocalization at age 16.6 months. The patient is waiting for complete repair.

There were 2 late mortality cases. The first patient developed a complete heart block after complete repair. A permanent pacemaker was inserted 1 month after complete repair, but the patient died of sudden cardiac arrest in another hospital, 1 year after the operation, possibly as a result of arrhythmia. The second patient had an airway problem after the central shunt procedure, and the patient underwent an anterior aortopexy and a graft interposition of the ascending aorta to relieve the airway compression.
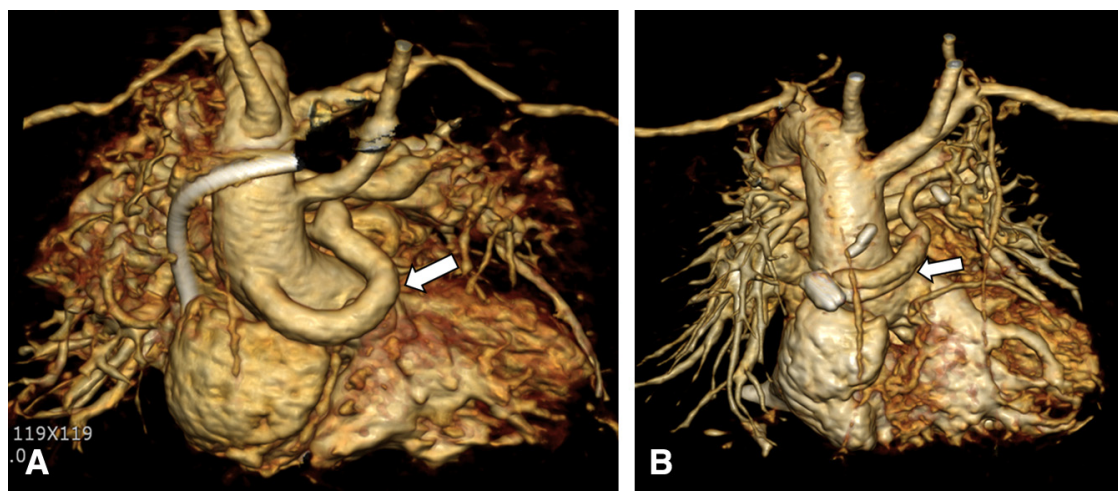

FIGURE 2. A, A U-shaped central shunt, and (B) a side-to-side aorto-ePTFE tube graft anastomosis. 


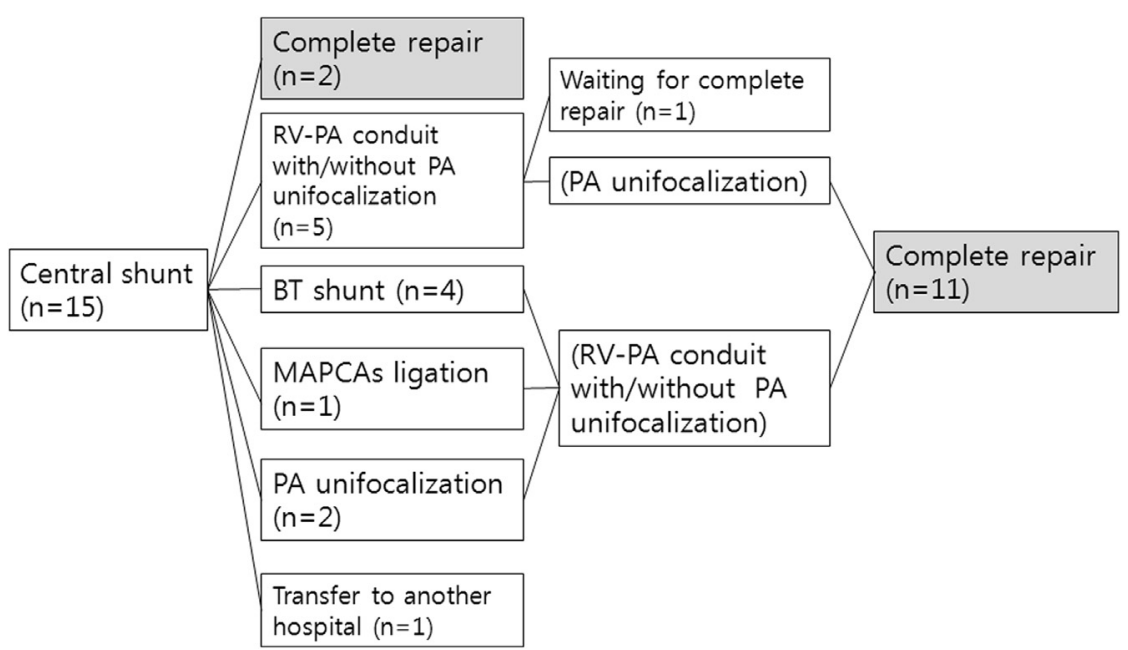

FIGURE 3. Stages of operations after the central shunt procedure. $R V$, Right ventricle; $P A$, pulmonary artery; $B T$, Blalock-Taussig; $M A P C A$, major aortopulmonary collateral artery.

The patient died of massive hemoptysis 33 days after complete repair. The overall survival rates were $92.9 \%$, $82.5 \%$, and $82.5 \%$, at 1,5 , and 10 years, respectively (Figure 5). During follow-up, reoperations were performed in 3 patients ( 3 of $14 ; 21.4 \%$ ). Pulmonary valve replacements were performed in 2, and RV-to-PA conduit change in 1 patient $68.7 \pm 37.9$ months after complete repair. Reinterventions were performed in 3 patients. All 3 patients underwent LPA balloon angioplasty. We were able to get right/left pressure ratios ( 0.57 and 0.56 , respectively) at the point of complete repair in 2 recent patients, and echocardiography data about the pressure gradient through tricuspid regurgitation in 4 patients $(38.4 \pm 14.2 \mathrm{~mm} \mathrm{Hg}$; range: $18-50 \mathrm{~mm} \mathrm{Hg}$ ). Four patients (4 of 12 survivors; $33.3 \%$ ) showed evidence of pulmonary hypertension at the final follow-up echocardiography.

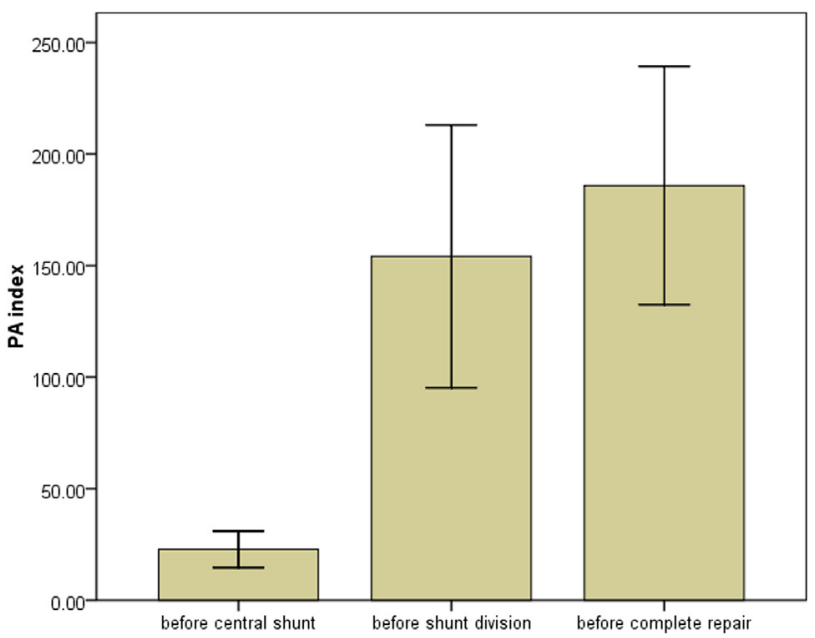

FIGURE 4. Changes of the pulmonary artery indices between the central shunt and complete repair. $P A$, Pulmonary artery.

\section{DISCUSSION}

This study summarizes our surgical experience with 15 patients who underwent the creation of a central shunt using an ePTFE tube graft as an initial palliation for pulmonary atresia with VSD and MAPCAs. There was no surgical mortality at the time of central shunt creation, and complete repair was achieved in 13 patients $(92.9 \%)$. There were 2 late mortality cases, but they were not related to the central shunt procedure. These results are similar to or better than other reported results, ${ }^{4-6,12}$ and indicate that the creation of a central shunt using an ePTFE tube graft as an initial palliation for pulmonary atresia with VSD and MAPCAs is effective for rehabilitation of diminutive PAs.

Patients with pulmonary atresia with VSD and MAPCAs have widely variable pathology, hemodynamics, and especially pulmonary vascular development, which include

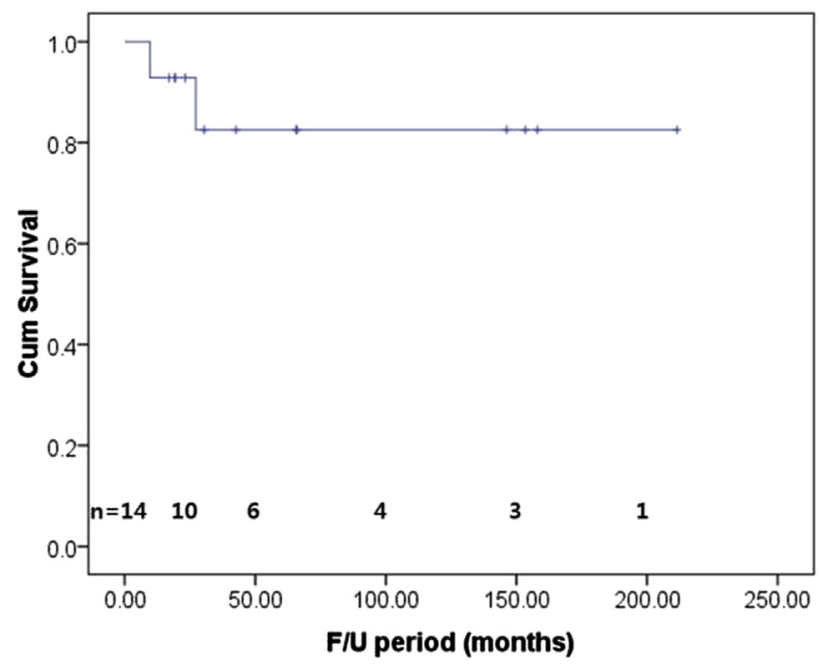

FIGURE 5. Kaplan-Meier survival curve after the central shunt procedure. cum, Cumulative; $F / U$, follow-up. 
the native PAs and the MAPCAs. Because each patient has distinct patterns of pulmonary vascularity, no one method is suitable for all patients. ${ }^{5}$ We think that it is essential to locate the small native PAs, and that rehabilitation of the diminutive PAs is possible in most cases. To define this anatomical variability, we routinely perform a cardiac catheterization with/without CT angiography before an initial operation. We identified 3 specific groups of patients (Figure 1), focusing on the second group (patients with diminutive PAs) in this study. This group usually has a PA index $<10-20 \mathrm{~mm}^{2} / \mathrm{m}^{2}$, and the patients underwent an initial central shunt procedure during early infancy (median age: 1.91 months), regardless of oxygen saturation level. Three patients underwent a ligation of the MAPCAs that were communicating with native PAs concomitantly as a result of overcirculation to the pulmonary vascular bed.

The central shunt procedure using an ePTFE tube graft, as an initial palliation for the management of pulmonary atresia with VSD and MAPCAs with diminutive PAs, has several advantages. First, using a U-shaped or straight ePTFE tube graft is effective for preventing overcirculation through the PAs. One of the main problems associated with a central shunt using a direct anastomosis between the ascending aorta and MPA (referred to as a "Melbourne shunt") is excessive pulmonary blood flow from the shunt. In the Roger Mee's series, $40 \%$ of the patients who underwent a central shunt using a direct anastomosis had signs of congestive heart failure, which did require antifailure treatment. ${ }^{7}$ However, our technique using an ePTFE tube graft showed no evidence of overcirculation of pulmonary blood flow after surgery. Second, this method is effective for growth of the PAs. In our study, the PA index before the initial central shunt was $22.7 \pm 13.2 \mathrm{~mm}^{2} / \mathrm{m}^{2}$, which increased to $149.4 \pm 86.6 \mathrm{~mm}^{2} / \mathrm{m}^{2}$ at the final recordings before shunt division. Moreover, the RPA and LPA grew evenly after our central shunt (Figure E1, $A$ and $B$ ).

Third, this method is very easy to perform, and no shunt-related complications or thrombosis occur after the operations, in our experience. We also think that the initial central shunt, compared with the RV-PA connection, ${ }^{13,14}$ has the advantages of avoiding use of the CPB and being easy to perform in small patients. In the patients who have very small PAs, performing an RV-PA connection is technically impossible, or at least very difficult. The disadvantage of a central shunt is that it prevents "antegrade" catheter intervention. However, catheter intervention can be performed after creating an RV-PA connection. In cases with a sizable MPA (the third group of patients), we also perform RV-PA connection as an initial procedure.

We made the central shunt using a U-shaped ePTFE tube graft in 13 patients, and a straight tube graft in 2 patients (Figure 2). The U-shaped tube graft is used when the
MPA segment is sizable, to make an end-to-end anastomosis between the divided MPA and one end of the graft. The opening of the divided MPA is usually smaller than that of the graft. Thus, we enlarge the opening of the MPA by making a fish-mouth incision or by further trimming the MPA distally. However, in cases with a very small MPA, we had to make a longitudinal incision at the anterior surface of the divided MPA and connect the graft to this incision. This graft was anastomosed to the ascending aorta in a side-to-side fashion with clipping of the other open end. We used this technique in 2 cases.

Our basic strategy for the management of pulmonary atresia with diminutive native PAs is to use the diminutive PAs as central PAs as much as possible. We think that every small PA can be rehabilitated and grown to be large enough to use as a central PA by imposing antegrade blood flow through the MPA. In addition, a higher success rate of unifocalization can be achieved by making an anastomosis of the MAPCAs to enlarged native PAs. Making an anastomosis of the MAPCAs to the small native PAs usually does not guarantee their patency, which then causes failure to recruit some part of the lung into pulmonary circulation, or requires frequent vascular interventions. Therefore, we are reluctant to perform one-stage total correction using unreliable MAPCAs tissue based on the small native PAs.

Interruption of communicating MAPCAs should be done as early as possible with either operations (clipping or ligation) or vascular interventions (embolization), to promote antegrade pulmonary blood flow through the central shunt. In addition, such early interruption prevents segmental pulmonary arterial hypertension. Our surgical method for the treatment of pulmonary atresia with VSD and MAPCAs with diminutive PAs is similar to the method used by a group in Melbourne, ${ }^{6,15,16}$ which advocated neonatal PA rehabilitation using a shunting regimen without unifocalization. However, the methods do have differences. First, we have focused on creating a central shunt using an ePTFE tube graft as an initial palliative procedure in the early infancy period. We believe that symmetrical distribution of pulmonary blood flow through MPA using a central shunt is very important. Second, we think that staging unifocalization after an initial central shunt procedure is mandatory for some of these patients because a part of the lung segments could be supplied uniquely by MAPCAs. We strongly believe that our strategy could allow us to perform a complete repair with a relatively high success rate compared with other reports. ${ }^{4-6,12,17}$

The present study does have limitations. A relatively small number of patients were enrolled in this study, and we do not have sufficient data about postoperative RV pressure, even though the performance status of most patients in the outpatient clinic is good. 


\section{CONCLUSIONS}

Creation of a central shunt using an ePTFE tube graft as an initial palliative procedure for patients with pulmonary atresia with VSD and MAPCAs is highly effective in rehabilitating the diminutive PAs, and a multistage approach focusing on rehabilitation of the diminutive PAs has produced encouraging results and good PA growth.

\section{References}

1. Amark KM, Karamlou T, O'Carroll A, MacDonald C, Freedom RM, Yoo SJ, et al. Independent factors associated with mortality, reintervention, and achievement of complete repair in children with pulmonary atresia with ventricular septal defect. J Am Coll Cardiol. 2006;47:1448-56.

2. Bull K, Somerville J, Ty E, Spiegelhalter D. Presentation and attrition in complex pulmonary atresia. J Am Coll Cardiol. 1995;25:491-9.

3. Reddy VM, Liddicoat JR, Hanley FL. Midline one-stage complete unifocalization and repair of pulmonary atresia with ventricular septal defect and major aortopulmonary collaterals. J Thorac Cardiovasc Surg. 1995;109: 832-44; discussion 44-5.

4. Reddy VM, McElhinney DB, Amin Z, Moore P, Parry AJ, Teitel DF, et al. Early and intermediate outcomes after repair of pulmonary atresia with ventricular septal defect and major aortopulmonary collateral arteries: experience with 85 patients. Circulation. 2000;101:1826-32.

5. Duncan BW, Mee RB, Prieto LR, Rosenthal GL, Mesia CI, Qureshi A, et al. Staged repair of tetralogy of Fallot with pulmonary atresia and major aortopulmonary collateral arteries. J Thorac Cardiovasc Surg. 2003;126:694-702.

6. Liava'a M, Brizard CP, Konstantinov IE, Robertson T, Cheung MM, Weintraub R, et al. Pulmonary atresia, ventricular septal defect, and major aortopulmonary collaterals: neonatal pulmonary artery rehabilitation without unifocalization. Ann Thorac Surg. 2012;93:185-91.

7. Watterson KG, Wilkinson JL, Karl TR, Mee RB. Very small pulmonary arteries: central end-to-side shunt. Ann Thorac Surg. 1991;52:1132-7.

8. Barozzi L, Brizard CP, Galati JC, Konstantinov IE, Bohuta L, d'Udekem Y. Side-to-side aorto-GoreTex central shunt warrants central shunt patency and pulmonary arteries growth. Ann Thorac Surg. 2012;92:1476-82.
9. Gates RN, Laks H, Johnson K. Side-to-side aorto-Gore-Tex central shunt Ann Thorac Surg. 1998;65:515-6.

10. Grosse-Wortmann L, Yoo SJ, van Arsdell G, Chetan D, Macdonald C, Benson L, et al. Preoperative total pulmonary blood flow predicts right ventricular pressure in patients early after complete repair of tetralogy of Fallot and pulmonary atresia with major aortopulmonary collateral arteries. J Thorac Cardiovasc Surg. 2013; 146:1185-90.

11. Honjo O, Al-Radi OO, MacDonald C, Tran KC, Sapra P, Davey LD, et al. The functional intraoperative pulmonary blood flow study is a more sensitive predictor than preoperative anatomy for right ventricular pressure and physiologic tolerance of ventricular septal defect closure after complete unifocalization in patients with pulmonary atresia, ventricular septal defect, and major aortopulmonary collaterals. Circulation. 2009;120: S46-52.

12. Song SW, Park HK, Park YH, Cho BK. Pulmonary atresia with ventricular septal defects and major aortopulmonary collateral arteries. Circ J. 2009;73: 516-22.

13. Metras D, Chetaille P, Kreitmann B, Fraisse A, Ghez O, Riberi A. Pulmonary atresia with ventricular septal defect, extremely hypoplastic pulmonary arteries, major aorto-pulmonary collaterals. Eur J Cardiothorac Surg. 2001;20:590-6; discussion 6-7.

14. Zhang Y, Hua Z, Yang $K$, Zhang $H$, Yan $J$, Wang $X$, et al. Outcomes of the rehabilitative procedure for patients with pulmonary atresia, ventricular septal defect and hypoplastic pulmonary arteries beyond the infant period. Eur J Cardiothorac Surg. 2014;46:297-303; discussion 303 .

15. Brizard CP, Liava'a M, d'Udekem Y. Pulmonary atresia, VSD and Mapcas: repair without unifocalization. Semin Thorac Cardiovasc Surg Pediatr Card Surg Annu. 2009;139-44.

16. d'Udekem Y, Alphonso N, Norgaard MA, Cochrane AD, Grigg LE, Wilkinson JL, et al. Pulmonary atresia with ventricular septal defects and major aortopulmonary collateral arteries: unifocalization brings no long-term benefits. J Thorac Cardiovasc Surg. 2005;130:1496-502.

17. Fouilloux V, Bonello B, Kammache I, Fraisse A, Mace L, Kreitmann B Management of patients with pulmonary atresia, ventricular septal defect, hypoplastic pulmonary arteries and major aorto-pulmonary collaterals: Focus on the strategy of rehabilitation of the native pulmonary arteries. Arch Cardiovasc Dis. 2012;105:666-75.

\section{EDITORIAL COMMENTARY}

\section{Shunt first: One way to do it}

Robert D. B. Jaquiss, MD

See related article on pages 515-20.

The management of children with ventricular septal defect, pulmonary valve atresia, diminutive central pulmonary arteries, and multiple aorto-pulmonary collateral

From the Division of Cardiothoracic Surgery, Duke University School of Medicine, Durham, NC.

Disclosures: Author has nothing to disclose with regard to commercial support.

Received for publication Nov 9, 2014; accepted for publication Nov 10, 2014; available ahead of print Dec 5, 2014.

Address for reprints: Robert D. B. Jaquiss, MD, Division of Cardiothoracic Surgery, Duke University School of Medicine, DUMC 3474, Durham, NC 27710 (E-mail: robert.jaquiss@duke.edu).

J Thorac Cardiovasc Surg 2015;149:520-1

0022-5223/\$36.00

Copyright (c) 2015 by The American Association for Thoracic Surgery

http://dx.doi.org/10.1016/j.jtcvs.2014.11.026 arteries is complex, because of the wide variability in pulmonary blood flow. Nowhere is the cliché that "every patient is unique" more apt than with this condition. In addition to the intrinsic anatomic variability that bedevils surgeons caring for such patients, recommendations are widely divergent for optimal provision of pulmonary blood supply. As to whether amalgamation of multiple aorto-pulmonary collateral arteries with native pulmonary arteries (unifocalization) should be performed if native pulmonary arteries are present, a reader of the Journal will have learned, in 2005, that unifocalization "brings no long-term benefits," ${ }^{\prime \prime}$ only to discover a few years later that "unifocalization ... is essential to achieve excellent outcomes." 2

A possible advantage of employing unifocalization is the potential to achieve a single-stage complete repair. ${ }^{3,4}$ 

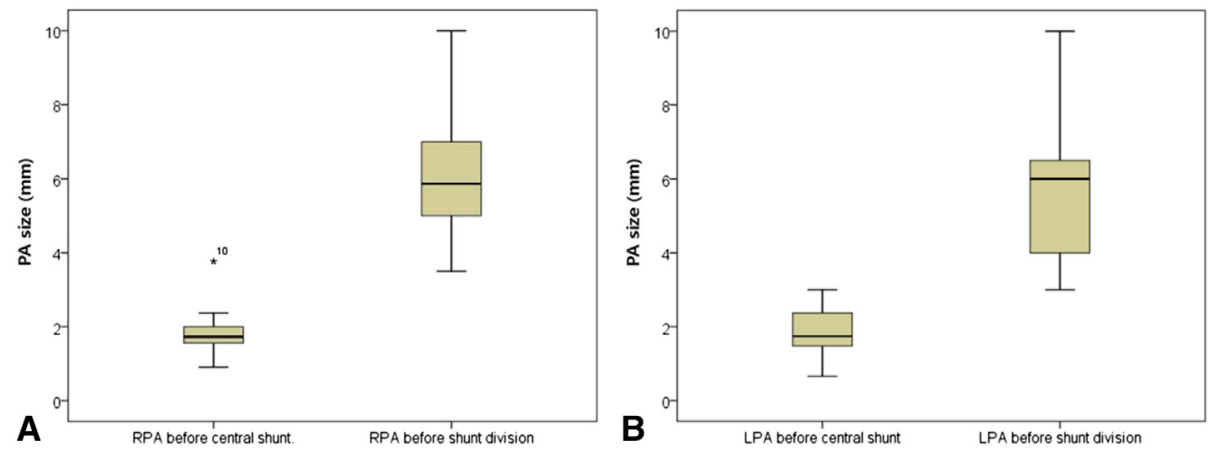

FIGURE E1. Growth of (A) the RPA, and (B) the LPA after central shunting. PA, Pulmonary artery; RPA, right pulmonary artery; $L P A$, left pulmonary artery. 